\title{
Structural Optimization of Payload Fairing Used for Space Launch Vehicles
}

\author{
H. Atar, and E. Acar
}

\begin{abstract}
Space Launch Vehicle (SLV) is a system to transport and place the Payloads (PL) such as satellites, experimental tools, and observation robots into desired orbit. PL are transported in Payload Fairing (PLF) that is a part of SLV and protects PL from environmental effects exposed during SLV's flight. PL capacity is the major criteria in design of SLVs. One option to increase PL capacity of SLV is to minimize PLF weight while protecting the volume allocated for PL. In this study, an Optimization System (OS) is developed to minimize PLF weight while maintaining the PLF structural design strong enough to protect PL from effects such as aerodynamic and inertial loads that emerged from flight conditions. Tabu Search is integrated to the OS to perform optimization. Structural analysis program is integrated to the OS to evaluate the structural strength. It is found that an optimized and structurally appropriate PLF configuration can be selected with Tabu Search integrated OS.
\end{abstract}

Index Terms - Structural optimization, payload fairing, Tabu Search, heuristic methods.

\section{INTRODUCTION}

Space Launch Vehicle (SLV) is a system that is used to transport Payloads (PL) like satellites, experimental vehicles, and observation robots to outside of atmosphere and place them to the desired orbit. SLV is composed of stages which has propulsion generators and Head Module (HM) which transport PL inside it. When the propellants inside of stages run out of, the stages are separated from SLV. After the stages separated from SLV, next stage starts to operate and generates the propulsion needed to transport PL to the target orbit. PL is transported inside PLF which protects PL from environmental effects exposed during flight.

Existing PLF design is given in Hata! Başvuru kaynağı bulunamadı. Diameter of present design is $2500 \mathrm{~mm}$. PLF is composed of cylindrical and conic section. PLF consists of longitudinal and transverse beams in it.

H. Atar, System Engineering and Technology Management Engineer in Space Systems Company, Ankara, Turkey, (e-mail: hakan.atar@ roketsan.com.tr).

E. Acar, TOBB University of Economics and Technology, Söğütözü 06560 Ankara, Turkey, (e-mail: acar@etu.edu.tr).
PLF consists of 20 pieces of longitudinal beam and 10 pieces of transverse beam in cylindrical section and 20 pieces of longitudinal and 4 pieces of transverse beam in conic section. PLF nose is conic shaped. PLF material is aluminum. The shell thickness of PLF is $2 \mathrm{~mm}$. The beams inside the PLF are Ibeam.

There exists various studies in literature on structural optimization of PLF. In the prior examples of PLF optimization, Analytical Hierarchy Process method was used. Different design and production criteria were considered while realizing this method. Best PLF composite material was chosen by scoring PLFs that produced from different composite materials according to the criteria [2]. Another method that used was hybrid heuristic method. Both Genetic Algorithm and Sequential Quadratic Programming were used in optimization system [11]. Also, HyperSizer program and finite element model were used to optimize Minotaur Launch Vehicle PLF design in relevant study [1]. MATLAB Genetic Algorithm Tool was used another study subjected structural optimization. In this study ANSYS analysis program was used to get structural analysis results $[5,8]$. 2-D roof and tower cage systems were optimized using this method.

In this study, the weight of a PLF is minimized while maintaining the PLF structural design strong enough under aerodynamic and inertial loads. Tabu Search is used to perform optimization, and a structural analysis program is integrated to optimization to evaluate the structural strength.

\section{THEORETICAL GROUND}

Firstly, mathematical model is constructed inside the PLF structural optimization study. Criteria which should be considered for optimization system is determined during this phase of study. Information related to mathematical model is given in Section A.

Optimization System (OS) is established by using inputs gathered from mathematical model. PL structural design is optimized by using OS. Detailed information related OS is given in Section B.

\section{A. Mathematical Model}

Decision variables and parameters of the mathematical model used for the PLF structural design optimization is given in TABLE I and TABLE II, respectively. The upper and lower bounds of the design variables are provided in TABLE IV. 


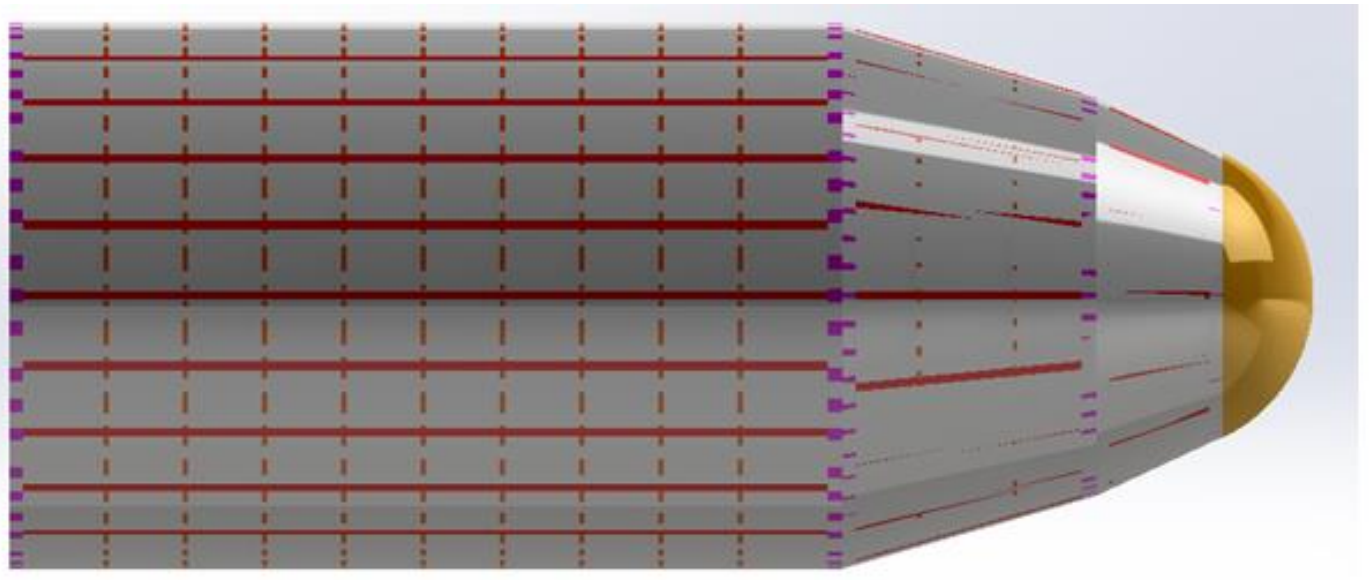

Fig 1. Payload Fairing (PLF)

TABLE I

DECISION VARIABLES OF PAYLOAD FAIRING STRUCTURAL DESIGN

\begin{tabular}{|c|c|c|}
\hline No & $\begin{array}{c}\text { Decision } \\
\text { Variable }\end{array}$ & Definition \\
\hline 1 & a & $\begin{array}{c}\text { Number of transverse beam in Cylindrical } \\
\text { Part of PLF }\end{array}$ \\
\hline 2 & c & $\begin{array}{c}\text { Number of transverse beam in conical } \\
\text { part of PLF }\end{array}$ \\
\hline 3 & materialType & $\begin{array}{c}\text { Material type used in PLF (Aluminum, } \\
\text { Magnesium, Steel) }\end{array}$ \\
\hline 4 & shellThickness & Shell thickness of PLF \\
\hline 5 & beamType & $\begin{array}{c}\text { Beam type of PLF ( I Beam, Z Beam, H } \\
\text { Beam, R Beam, C Beam, T Beam, L } \\
\text { Beam, W Beam) }\end{array}$ \\
\hline 6 & beamLength & Beam length of PLF \\
\hline
\end{tabular}

TABLE II.

MATHEMATICAL MODEL PARAMETERS OF PAYLOAD FAIRING STRUCTURAL DESIGN

\begin{tabular}{|c|c|c|}
\hline No & Parameter & Definition \\
\hline 1 & beamArea $_{\mathrm{i}}$ & Beam section area for beam type $\mathrm{i}$ \\
\hline 2 & beamLength_a & $\begin{array}{c}\text { Beam length of beam used in cylindrical } \\
\text { section }\end{array}$ \\
\hline 3 & beamLength_c $_{1}$ & $\begin{array}{c}\text { Beam length of beam used in conic } \\
\text { section }\end{array}$ \\
\hline 4 & shellArea $_{\mathrm{j}}$ & Section area of shell number $\mathrm{j}$ \\
\hline 5 & Smax $_{\mathrm{k}}$ & $\begin{array}{c}\text { Stress limit of material type } \mathrm{k} \text { used in } \\
\text { PLF }\end{array}$ \\
\hline 6 & Tmax $_{\mathrm{k}}$ & $\begin{array}{c}\text { Tip deflection limit of material type } \mathrm{k} \\
\text { used in PLF }\end{array}$ \\
\hline 7 & yogunlukm & Density of material m used in PLF \\
\hline
\end{tabular}

TABLE III.

INITIAL VALUES AND LOWER-UPPER LIMIT OF VARIABLES

\begin{tabular}{|c|c|c|c|c|}
\hline Variable & Unit & $\begin{array}{c}\text { Initial } \\
\text { Value }\end{array}$ & $\begin{array}{c}\text { Upper } \\
\text { Limit }\end{array}$ & $\begin{array}{c}\text { Lower } \\
\text { Limit }\end{array}$ \\
\hline $\mathrm{a}$ & piece & 10 & 1 & 15 \\
\hline $\mathrm{c}$ & piece & 4 & 1 & 6 \\
\hline MaterialType & N/A & $\mathrm{Al}$ & N/A & N/A \\
\hline ShellThickness & $\mathrm{mm}$ & 2 & 1 & 2.5 \\
\hline BeamType & N/A & I & N/A & N/A \\
\hline BeamLength & $\mathrm{mm}$ & 20 & 10 & 25 \\
\hline
\end{tabular}

N/A: Not Applicable
Mathematical model of the PLF structural optimization is given below;

\section{Objective Function}

$$
\begin{aligned}
& \min \sum \text { materialType }_{m} * \text { density }_{m} \\
& \begin{array}{c}
*\left(\sum_{i} \text { beamArea }_{i} * \text { beamLength }_{a} * a\right. \\
\\
* \text { beamType }_{i}
\end{array} \\
& +\sum_{i} \sum_{l}^{* \text { beamArea }_{i}} \\
& \text { * beamLength_c } c_{i} * c * \text { beamType }_{i} \\
& \left.+\sum_{j} \text { shellArea }_{j} * \text { shellThickness }\right)
\end{aligned}
$$

\section{Constraints}

$$
\begin{gathered}
S<\sum_{m} \text { Smax }_{m} * \text { materialType }_{m} \\
T<\sum_{m} \operatorname{Tmax}_{m} \\
a>1 \\
c>1
\end{gathered}
$$

beamLength $\geq 10 \mathrm{~mm}$

$$
\text { a, c integer }
$$

Equation (1) is the objective function of the mathematical model. The aim of PLF structural design optimization problem is minimizing the mass, which is the summation of beam and shell masses. The mass values are obtained by multiplying the 
densities and the volumes of the PLF cylindrical and conical section beams and PLF shell parts.

Equations (2), (3), (4), (5), (6), (7), (8), (9) and 10 are the constraints of mathematical model. Equation (2) constrains the stresses developed at the structural parts. This constraint is used to make the PLF structural design strong enough against to the stress emerged during flight. The ' $\mathrm{S}$ ' value used in this term denotes the stress and it is obtained from PLF structural analysis. $S_{\max }$ value in Equation (2) is the maximum allowable stress of material represented by materialType $\mathrm{m}_{\mathrm{m}}$.

Equation (3) constrains the deflections of the structural parts. This constraint is used to make the PLF structural design stiff enough. The ' $T$ ' value used in this term denotes the deflection is obtained from PLF structural analysis. $T_{\max }$ value in Equation (3) is the maximum allowable deflection of PLF.

Equation (4) constrains the number of transverse beam used in the cylindrical section of PLF. This constraint ensures the use of at least two transverse beams in cylindrical section. Equation (5) constraints the number of transverse beam used in the conical section of PLF. This constraint ensures the use of at least two transverse beams in conical section.

Equation (6) constrains the thickness of shell. The minimum value of this shell thickness is determined as $1 \mathrm{~mm}$ (due to manufacturing limits).

Equation (7) guarantees to choose at least and only one material type for PLF. There alternatives are evaluated during optimization. These alternatives are aluminum, steel and magnesium. Equation (8) guarantees to choose at least and only one beam type for PLF. The beam types evaluated in OS are ' $Z$ ' beam, 'C' beam, ' $T$ ' beam, 'L' beam, ' $W$ ' beam, 'I' beam and 'R' beam.

Equation (9) constrains the length of beam used for PLF design. The minimum value of this beam length is determined as $10 \mathrm{~mm}$.

Equation (10) defines that variables ' $a$ ' and ' $c$ ' can take only integer values.

When the mathematical model is inspected, structural analysis program should integrated to the OS to obtain the stress ' $S$ ' and deflection ' $T$ ' values. Details of the OS is explained next.

\section{i. Optimization System (OS)}

PLF structural optimization study contains a multidisciplinary engineering approach. The OS developed in this scope includes more than one subsystem that belongs to different engineering branches.

OS basically contains the following three subsystems;

- Heuristic Subsystem,

- Design Subsystem,

- Analysis Subsystem.

The flow chart explaining the working principle of OS is given in Hata! Başvuru kaynağı bulunamadı.

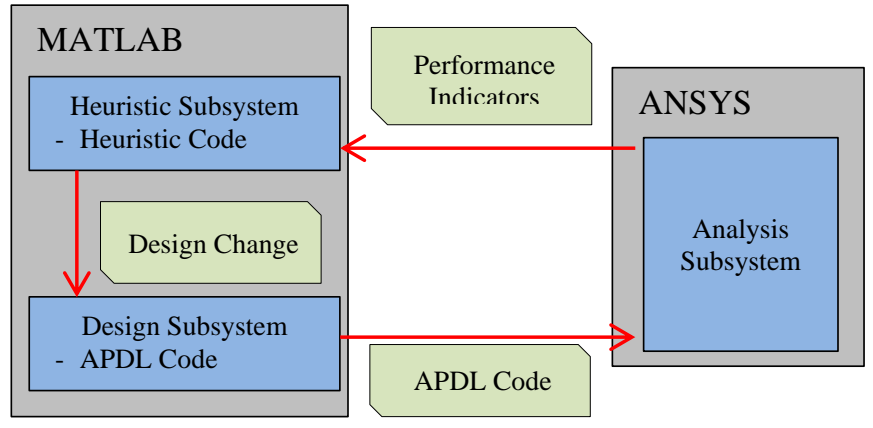

Fig 2. Flow Chart of Optimization System

Design, Analysis and Heuristic Subsystems work together and each subsystem gets the inputs, works over the inputs, creates the outputs and gives it to next subsystem. Each subsystem working principle is explained in the following sections.

\section{a. Heuristic Subsystem}

The inputs of Heuristic Subsystem are the existing PLF design and the performance indicators. The output of this subsystem is the design change of existing PLF design. This output is given to Design Subsystem to update the PLF design. All design variables describing the PLF design are evaluated as decision variables in Heuristic Subsystem. These decision variables are transformed into Heuristic Subsystem optimization moves and so objective function of PLF structural design is become optimized. Heuristic method used in Heuristic Subsystem is coded, and the whole logic and scanning operations of the heuristic method are realized using MATLAB.

Tabu Search is determined as a suitable heuristic method for PLF structural optimization. Tabu Search is coded in MATLAB to be integrated to OS. Initial values, neighbors and lower/upper limits of decision (design) variables used in Tabu Search are given in

TABLE IV.

NEIGHBORS AND STEPS OF VARIABLES

\begin{tabular}{|c|c|c|}
\hline Variable & Step & Neighbors \\
\hline $\mathrm{a}$ & Increasing and decreasing 1 & $\mathrm{a}+1, \mathrm{a}-1$ \\
\hline $\mathrm{c}$ & Increasing and decreasing 1 & $\mathrm{c}+1, \mathrm{c}-1$ \\
\hline materialType & \multicolumn{2}{|c|}{ Other all materials } \\
\hline shellThickness & Increasing and decreasing 0,1 & $\begin{array}{c}\text { shellThickness+0.1, } \\
\text { shellThickness -0.1 }\end{array}$ \\
\hline beamType & \multicolumn{2}{|c|}{ Other all beam types } \\
\hline beamLength & Increasing and decreasing 1 & $\begin{array}{c}\text { beamLength+1, } \\
\text { beamLength -1 }\end{array}$ \\
\hline
\end{tabular}

In the first part of Tabu Search, the moves on the existing PLF design decision variables given in TABLE IV are realized and new PLF designs are obtained. The APDL codes of the new PLF designs are written to the text document. The text documents created for all neighbors are given to the ANSYS analysis program as an input. ANSYS analysis program conducts the structural analysis and gives the results of 
performance indicators in the form of a text document to the Heuristic Subsystem to be evaluated.

If both maximum stress and maximum deflection values are smaller than the desired values, the PLF design is assessed as feasible and the move is realized on PLF design. The assessment process is completed for all neighbors. The objective function values are calculated for all feasible PLF neighbors and the neighbor having the best objective function value is determined as the selected neighbor.

The move of selected neighbor is controlled whether it is in Tabu list or not in the next phase. In the continuation of this phase;

- If the selected neighbor move is in the Tabu list, the selected neighbor is controlled whether it is better than the best solution or not.

o If the selected neighbor has better objective function value than the best solution, the selected neighbor is accepted as the next solution and the best solution, and the iteration number is increased.

o If the selected neighbor is not better than the best solution, the next better neighbor solution is accepted and this phase is repeated.

- If the selected neighbor move is not in the Tabu list, the selected neighbor is controlled whether it is better than the best solution or not.

o If the selected neighbor is better than the best solution, the selected neighbor is accepted as the next solution and the best solution, and the iteration number is increased.

o If the selected neighbor is not better than the best solution, the selected neighbor is accepted as the next solution, and the iteration number is increased.

Tabu list is updated in the next phase. The new move of the selected neighbor is added to Tabu list and the oldest move in the Tabu list is deleted. Neighbor moves are stored in the Tabu list to preserve repetition of the same move. Thus, different parts of the solution cluster can be searched and evaluated. This provides the diversification over the problem. In case the solution is better than the best solution despite it is in the Tabu list, this solution is set as next solution. This situation is called as aspiration criteria and this process provides intensification over the solution cluster. 3.

The flowchart of the process described above is given in Fig

\section{b. Design Subsystem}

This subsystem applies the design changes to the PLF structural design during the optimization iterations. Design changes include changing the dimensions of PLF mechanical components, the material of PLF and the configuration of PLF. These changes are reflected to the design by using ANSYS Parametric Design Language (APDL).

APDL is coded by using MATLAB and shared with ANSYS. In each iteration of the OS, the design is updated automatically with APDL parametric definition. Design changes, which are the output of Heuristic Subsystem, become inputs of the Design Subsystem to update the design. Updated APDL, which is the output of Design Subsystem, is given to Analysis Subsystem as an input.

\section{c. Analysis Subsystem}

PLF structural analysis is realized to determine the performance indicators (e.g., stresses and deflections) of the existing or the updated PLF design. Performance indicators show the effectiveness of the design and they are evaluated to determine whether the design is feasible or not.

PLF structural analysis is conducted using ANSYS. APDL code of the updated APDL design is transferred to the Analysis Subsystem from Design Subsystem. ANSYS computes the performance indicators of the updated design and these performance indicators are transferred to Heuristic Subsystem as an input.

\section{RESULTS AND DISCUSSION}

The optimization runs are conducted by using the OS. The runs are executed by using a workstation with Intel Core i7 64bit processer and 8GB RAM. The results of the optimization runs are given in TABLE V. It is observed that the PLF mass can be reduced from $180.51 \mathrm{~kg}$ to $75.58 \mathrm{~kg}$ (reduced by $58.7 \%$ ).

TABLE V

RUN RESULTS FOR DIFFERENT NUMBER OF ITERATIONS

\begin{tabular}{|c|c|c|c|c|c|c|c|}
\hline $\begin{array}{c}\text { Numbe } \\
\mathbf{r} \text { of } \\
\text { Iteratio } \\
\mathbf{n}\end{array}$ & $\mathbf{a}$ & $\mathbf{c}$ & $\begin{array}{c}\text { Materia } \\
\text { I Type }\end{array}$ & $\begin{array}{c}\text { Shell } \\
\text { Thicknes } \\
\mathbf{s}\end{array}$ & $\begin{array}{c}\text { Bea } \\
\mathbf{m} \\
\mathbf{T y p e}\end{array}$ & $\begin{array}{c}\text { Beam } \\
\mathbf{L e n g t} \\
\mathbf{h} \\
\mathbf{m m})\end{array}$ & $\begin{array}{c}\text { Objectiv } \\
\mathbf{e} \\
\text { Function } \\
\text { Value(kg } \\
)\end{array}$ \\
\hline 0 & $\begin{array}{c}1 \\
0\end{array}$ & 4 & 1 & 2 & 1 & 20 & 180,51 \\
\hline 5 & 1 & 4 & 3 & 1,6 & 1 & 20 & 144,89 \\
\hline 10 & 1 & 4 & 3 & 1,1 & 1 & 20 & 100,03 \\
\hline 20 & 1 & 4 & 3 & 1 & 1 & 11 & 80,83 \\
\hline 50 & 7 & 6 & $\mathrm{Mg}$ & 1 & 3 & 10 & 75,58 \\
\hline
\end{tabular}

TABLE $\mathrm{V}$ also shows that the shell thickness is reduced to its lower limit of $1 \mathrm{~mm}$. Another change observed for the PLF design is the material type. Magnesium is used instead of aluminum and this change decreases the PLF weight by $40 \%$.

It can be seen that the decision variables a and $\mathrm{c}$ are also design critical in terms of PLF flight loads. It is found that the optimizer reduces the number of beams in the cylindrical part (a) and increases the number of beams in the conical part (c) to decrease the PLF weight while maintaining the stresses and deflections below the specified constraint values.

Another criteria that can be used to evaluate the performance of OS is the run time of the system. The run times are listed in TABLE VI, which shows that the run time increases exponentially with respect to the iteration number. Therefore, it is required to keep the iteration number as low as 
possible. The evolution of the objective function value through iterations are depicted in Fig 4, which shows that 30 iterations are enough for OS to get near optimal solutions. 


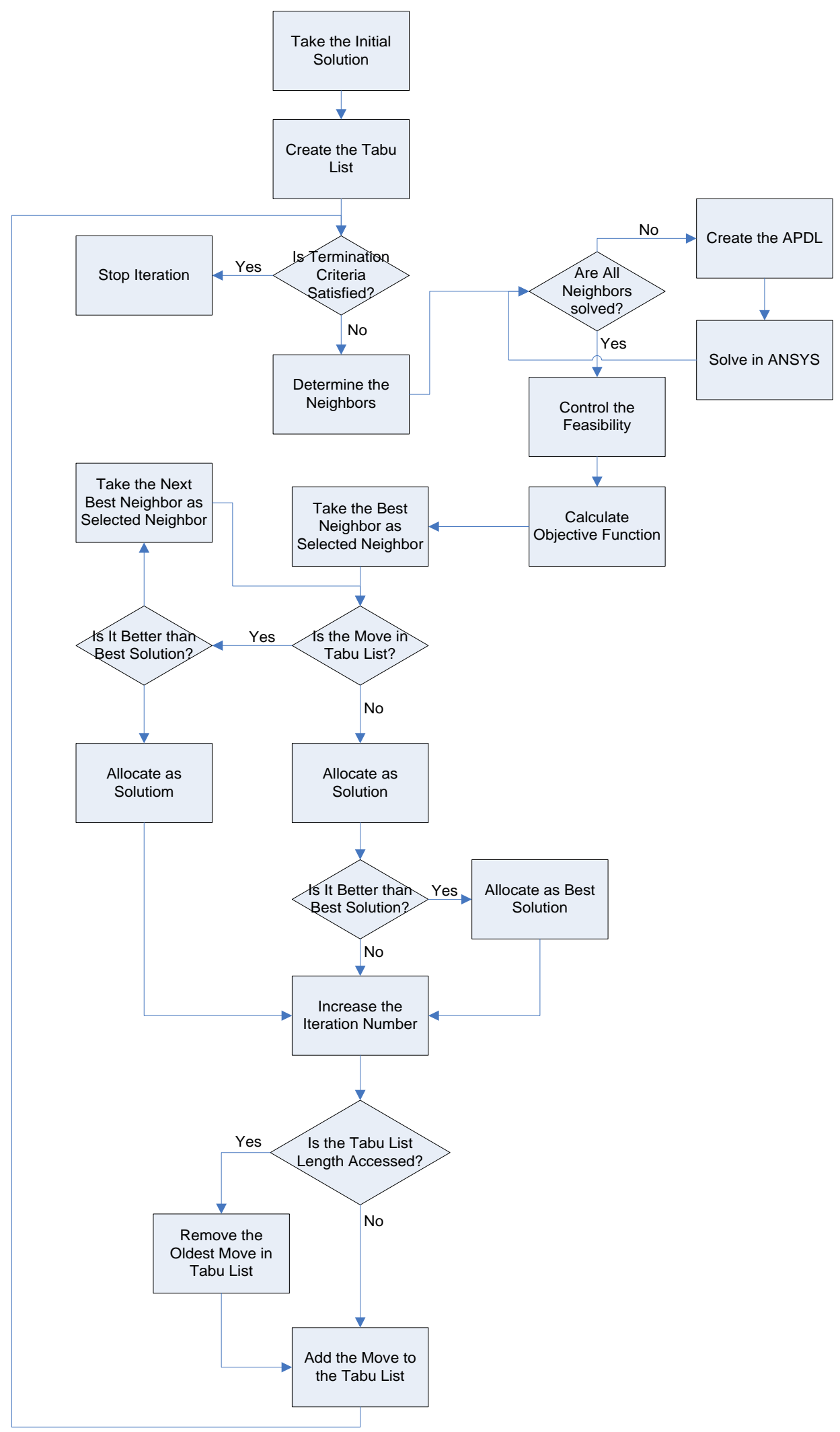

Fig 3. Optimization Subsystem Flow Chart 
TABLE VI.

THE RUN TIMES FOR DIFFERENT ITERATION NUMBERS

\begin{tabular}{|c|c|}
\hline Iteration Number & Run Time (second) \\
\hline 5 & 503 \\
\hline 10 & 1086 \\
\hline 20 & 3174 \\
\hline 50 & 10573 \\
\hline
\end{tabular}

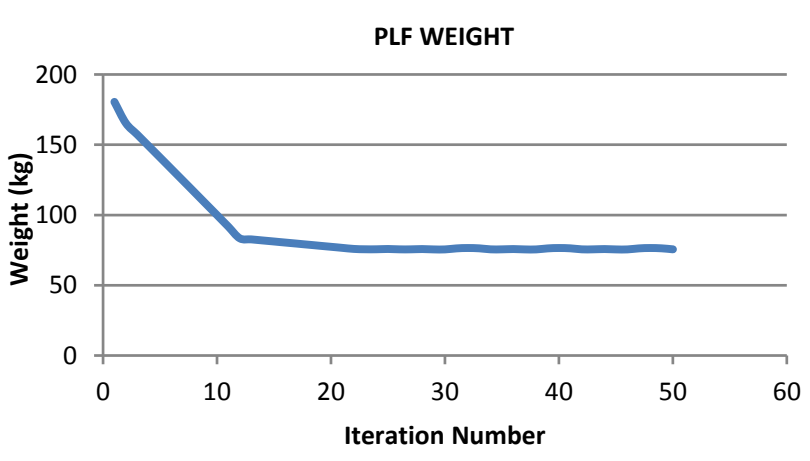

Fig 4. PLF Weight Change for Different Iteration Numbers

\section{CONCLUSION}

In this study, Payload Fairing (PLF) used in Space Launch Vehicles was optimized using Tabu Search, which is a heuristic method. Optimization results showed that the optimum PLF design should have $1 \mathrm{~mm}$ shell thickness, and that PLF material should be aluminum. PLF beam length should be $10 \mathrm{~mm}$. The number of beams in the conical section should be six, and the number of beams in the cylindrical section should be seven. This design changes resulted in $58.7 \%$ weight reduction. It was also found that 30 iterations were enough for OS to get near optimal solutions and high performance from OS, and that Tabu Search can be used to optimize PLF design and to get the good solutions efficiently.

Future study could focus on using other heuristic methods (e.g., Genetic algorithm, simulated annealing, etc.) and the most suitable method for PLF design could be determined.

\section{ACKNOWLEDGMENT}

The study is selected from National Engineering Research Symposium 2015 (Ulusal Mühendislik Araştırmaları Sempozyumu) UMAS 2015 (Duzce University).

\section{REFERENCES}

[1] Krivanek T.M., Yount B.C. (2012), Composite Payload Fairing Structural Architecture Assessment and Selection, E-18094, NASA Glenn Research Center, Cleveland.

[2] Wenger P.M., Higgins J. E., VanWest B. P. (2002) Application of Advanced Grid-Stiffened Structures Technology to the Minotaur Payload Fairing, AIAA 2002-1336, 1061-1067.

[3] Irish Angelin S., Senthilkumar S. (2013) Aerodynamic Shaping of Payload Fairing for Launch Vehicle, Journal of Spacecraft and Rockets, Vol. 50, No. 6, pp. 1299-1304. doi: 10.2514/1.A32838.

[4] Reisenthel P. H. ,Childs R. E., Higgins J. E., (2007) Surrogate-Based Design Optimization of a Large Asymetric Launch Vehicle Payload Fairing, 46th Aerospace Sciences Meeting and Exhibit, 2007-0361, ISSN: 10877215
[5] Togan V., Seyhun M. O., Daloglu A. (2015) A Comparative Study For The Optimum Design of StructuresUsing GeneticAlgorithm, www.researchgate.bet, search on 15th of June.

[6] Kargahi, M. and Anderson, J. (2006) Structural Weight Optimization with Tabu Search. Earth \& Space 2006: pp. 1-8. doi: 10.1061/40830(188)163.

[7] Connor, A.M., Seffen, K.A., Clarkson, P.J. \& Parks, G.T. (1999) Efficient Optimisation Of Structures Using Tabu Search, Proceedings of the 1st ASMO/ISSMO Conference on Engineering Design Optimization, 127-134

[8] A. Gauchía, B.L. Boada, M.J.L. Boada and V. Díaz (2014). Integration of MATLAB and ANSYS for Advanced Analysis of Vehicle Structures, MATLAB Applications for the Practical Engineer, Mr Kelly Bennett (Ed.), ISBN: 978-953-51-1719-3

[9] Zafar N., Linshu H., (2010) Multidisciplinary Design Optimization of Solid Launch Vehicle Using Hybrid Algorithm, 51st AIAA/ASME/ASCE/AHS/ASC Structures, Structural Dynamics, andMaterials Conference, DOI: 10.2514/6.2010-3010

[10] Inc. PADT, Strain J.,"Introduction to the ANSYS Parametric Design Language (APDL): A Guide to the ANSYS Parametric Design", CreateSpace Independent Publishing Platform; 1 edition, ISSN: 146641135X

[11] Bayley D. J., Hartfield R J., Burkhalter J E., , Jenkins R M.(2008), Design Optimization of a Space Launch Vehicle Using a Genetic Algorithm, Journal of Spacecraftand Rockets, Vol. 45, No. 4 , pp. 733740.doi: $10.2514 / 1.35318$.

\section{BIOGRAPHIES}

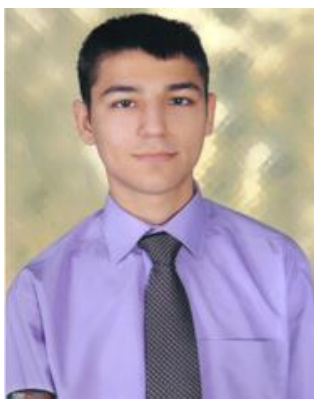

Hakan ATAR was born in Aydın, Turkey in 1990. He received his BS in Industrial Engineering and double major BS in Mechanical Engineering at the TOBB University of Economics and Technology of Turkey where he is currently receiving his MS degree since 2013.

Since 2013 he is serving as System Engineering and Technology Management Engineer in Space Systems Company in Ankara. He is working as system engineering responsible of the projects and technology management engineer of Engineering Directorate. His research area includes design optimization of mechanical systems. His research on design optimization of mechanical system is focused on heuristic methods.

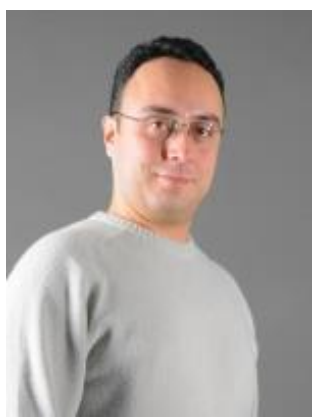

Erdem ACAR received his BS and MS degrees in Aerospace Engineering at the Middle East Technical University in 1999 and 2002, respectively, and his $\mathrm{PhD}$ degree in the same field at the University of Florida in 2006. He served as postdoctoral research associate at the Center for Advanced Vehicular Systems of the Mississippi State University from 2006 to 2008. $\mathrm{He}$ began his academic career in 2008 at the TOBB University of Economics and Technology of Turkey, where he is currently an Associate Professor at the Department of Mechanical Engineering. He is actively engaged in teaching and research. His primary areas of teaching include structural analysis and reliability assessment of mechanical systems. His research efforts are focused on design optimization of mechanical systems, with strong emphasis on reliability-based design optimization and surrogate-based design optimization. He has published around sixty refereed journal and conference papers in the above areas. He is an associate fellow of AIAA, and a member of the AIAA Non Deterministic Approaches Technical Committee. 